Journal of Zhejiang University-SCIENCE A (Applied Physics \& Engineering)

ISSN 1673-565X (Print); ISSN 1862-1775 (Online)

www.zju.edu.cn/jzus; www.springerlink.com

E-mail: jzus@zju.edu.cn

\title{
Review:
}

\section{Constitutive models of artificial muscles: a review*}

\author{
Hui-ming $\mathrm{WANG}^{1,2}$, Shao-xing QU $\$ 1,2$ \\ $\left({ }^{1}\right.$ Key Laboratory of Soft Machines and Smart Devices of Zhejiang Province, Hangzhou 310027, China) \\ $\left({ }^{2}\right.$ Department of Engineering Mechanics, Zhejiang University, Hangzhou 310027, China) \\ E-mail: wanghuiming@zju.edu.cn; squ@zju.edu.cn
}

Received July 13, 2015; Revision accepted Nov. 4, 2015; Crosschecked Dec. 10, 2015

\begin{abstract}
Artificial muscles are materials which possess muscle-like characteristics; they have many promising applications and many materials have been exploited as artificial muscles. In this review, the artificial muscles discussed are confined to dielectric elastomers and responsive gels. We focus on their constitutive models based on free energy function theory. For dielectric elastomers, both hyperelastic and visco-hyperelastic models are involved. For responsive gels, we consider different kinds of gels, such as hydrogel, $\mathrm{pH}$-sensitive gel, temperature-sensitive gel, polyelectrolyte gel, reactive gel, etc. With an accurate, reliable, and powerful constitutive model, exact theoretical analysis can be achieved and the important intrinsic characteristics of artificial muscle based systems can be revealed.
\end{abstract}

Key words: Constitutive model, Artificial muscle, Dielectric elastomer, Responsive gel, Free energy function http://dx.doi.org/10.1631/jzus.A1500207

CLC number: O34; O39

\section{Introduction}

Living animals can perform many kinds of moving activities, such as standing, walking, running, climbing, jumping, kicking, catching, rotating, etc. All these motions are accomplished with the aid of muscles. Muscles have the ability to generate forces and are the main internal motors of the movement of living animals (Knudson, 2007). Natural muscles are elastic and flexible and have high mechanical strength. They take various forms. Materials or devices which have muscle-like characteristics are described as artificial muscles (Otake, 2010). The two main noticeable properties of artificial mus-

\footnotetext{
¿ Corresponding author

* Project supported by the National Natural Science Foundation of China (Nos. 11222218, 11372273, and 11321202), the Zhejiang Provincial Natural Science Foundation of China (Nos. LY13A020001 and LZ14A020001), and the Fundamental Research Funds for the Central Universities, China

(D) ORCID: Hui-ming WANG, http://orcid.org/0000-0002-93444609; Shao-xing QU, http://orcid.org/0000-0002-1217-4644

(C) Zhejiang University and Springer-Verlag Berlin Heidelberg 2016
}

cles are "soft" and "active". In modern techniques, many materials have been exploited as artificial muscles in practical engineering applications, for example, dielectric elastomer electroactive polymers, ionic electroactive polymers, ionic polymeric gels, polyelectrolyte hydrogels, conductive polymers, liquid crystal elastomer materials, electrorheological materials, magnetorheological materials, shape memory alloys, small memory polymers, etc. (Shahinpoor et al., 1998; 2007; Shahinpoor, 2003; Bassil et al., 2008; O'Halloran et al., 2008; Wallace et al., 2009; Carpi et al., 2011a; Aw and McDaid, 2014; Kwon et al., 2014; Mutlu et al., 2014).

As is well known, theoretical modeling and simulation play an important role in understanding the functionality of artificial muscles. To improve the performance of biomimetic robots (Kim et al., 2013), artificial hands (Balasubramanian and Santos, 2014), tunable lenses (Carpi et al., 2011b), etc., it is important to carry out qualitative or quantitative analysis. In the theoretical analysis, it is crucial to develop and use accurate, reliable, and powerful constitutive models. 
In this review, we will focus on constitutive models for dielectric elastomers and responsive gels. The models are based on free energy function theory.

\section{Constitutive models of a dielectric elastomer}

\subsection{Hyperelastic model of a dielectric elastomer}

Dielectric elastomers belong to one class of soft active materials. They deform largely through expanding in area and reducing in thickness in response to an applied voltage or external load. The large strain justifies dielectric elastomers being called artificial muscle. Various transducers for a dielectric elastomer membrane sandwiched between two soft electrodes (usually carbon grease) have been developed.

A decade ago, Pelrine et al. (2000) discovered that a dielectric elastomer can be actuated at a strain larger than $100 \%$ by applying a voltage. This discovery inspired many scientists and engineers to investigate and develop dielectric elastomers and great improvements have been made. The principle of operation of a dielectric elastomer membrane is shown in Fig. 1.

(a)

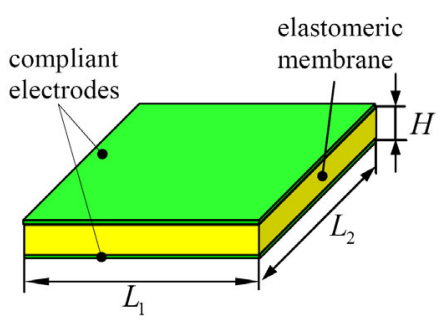

(b)

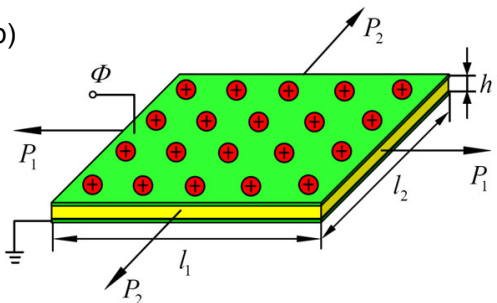

Fig. 1 Schematics of a dielectric elastomer in different states

In the reference state (a), an elastomeric membrane of sides $L_{1}$ and $L_{2}$ and thickness $H$ is sandwiched between two compliant electrodes. In the deformed state (b), the dielectric elastomer deforms to sides $l_{1}$ and $l_{2}$ and thickness $h$ when subjected to the mechanical loadings $P_{1}$ and $P_{2}$ and a high voltage $\Phi$
Under dead load $P=25.5 \mathrm{~g}$ and at voltage ramp rate $500 \mathrm{~V} / \mathrm{s}$, Huang et al. (2012a) achieved the areal strain of $488 \%$. Not long after, this record was broken by Li et al. (2013). They obtained a giant voltage-induced area expansion at $1692 \%$ by inflating a dielectric membrane which was mounted on a chamber. Zou et al. (2014) performed experiments and simulations on the active shape control of dielectric elastomer structures with various $2 \mathrm{D}$ patterned electrodes by means of an applied voltage. In their experiment, the dielectric elastomer membrane with a pattern of $2 \mathrm{D}$ electrodes was mounted on an air chamber. They observed a large voltage-induced deformation and the coexistence of two stable states in the dielectric elastomer. Qu et al. (2012) observed stretching rate dependent behaviors of dielectric elastomer membranes (VHB ${ }^{\text {TM9473) }}$ subjected to pure shear-like loading and electric loading simultaneously. Their experimental observations were compared with theoretical predictions by a viscoelastic model. It is known that there are multiple large-scale failure modes in dielectric elastomers, such as material strength failure, electric breakdown, loss of tension, electromechanical instability, etc. (Plante and Dubowsky, 2006; Zhao and Suo, 2007; Liu et al., 2008; 2009a; Leng et al., 2009; Zhou et al., 2013; Joglekar, 2014; Li et al., 2014; Liu et al., 2014a; Mao et al., 2014; Zhu, 2015). To prevent failure and to harness the large deformation of dielectric elastomers, it is necessary to construct a theoretical framework. Based on parameter analysis and loading design, many sensors (Jung et al., 2008; Son and Goulbourne, 2009; Gisby et al., 2013; Liu J.J. et al., 2015), actuators (Carpi and Rossi, 2004; Carpi et al., 2005; 2007; Aschwanden and Stemmer, 2006; Plante and Dubowsky, 2007; Shankar et al., 2007; Wissler and Mazza, 2007; Biddiss and Chau, 2008; Moscardo et al., 2008; Kovacs et al., 2009; Liu et al., 2009b; Carpi et al., 2010; Fang et al., 2010; Akbari and Shea, 2012; Son et al., 2012; Giousouf and Kovacs, 2013; Haus et al., 2013; La and Lau, 2013; Shian et al., 2013; Hunt et al., 2014; Lu et al., 2014; Nguyen C.H. et al., 2014; Nguyen C.H. et al., 2014; Mao et al., 2015), and energy harvesters (Koh et al., 2009; 2011; Liu et al., 2010; McKay et al., 2010; 2011; Ahnert et al., 2011; Kaltseis et al., 2011; Wang et al., 2012a; Chiba et al., 2013; Huang et al., 2013; Graf et al., 2014) with high performance have been achieved. 
The mechanical deformation behavior of a dielectric elastomer can be well predicted by one or some of the above models under specific conditions. In order to study the electromechanical behavior of dielectric elastomers, Suo (2010) presented a nonlinear field theory of dielectric elastomers. The condition of thermodynamic equilibrium of a dielectric elastomer demands (Suo et al., 2008):

$$
\delta W(\boldsymbol{F}, \tilde{\boldsymbol{D}})=\boldsymbol{s} \delta \boldsymbol{F}+\tilde{\boldsymbol{E}} \delta \tilde{\boldsymbol{D}},
$$

where $W$ is the free energy density function. $s$ is the nominal stress tensor and $\boldsymbol{F}$ is the deformation gradient tensor. $\boldsymbol{s}$ is work conjugate to $\boldsymbol{F}$. $\tilde{\boldsymbol{E}}$ is the nominal electric field vector and $\tilde{\boldsymbol{D}}$ is the nominal electric displacement vector. Also, $\tilde{\boldsymbol{E}}$ is work conjugate to $\tilde{\boldsymbol{D}}$ (Suo et al., 2008). Then mathematically, the constitutive equations are obtained as:

$$
\boldsymbol{s}=\frac{\partial W(\boldsymbol{F}, \tilde{\boldsymbol{D}})}{\partial \boldsymbol{F}}, \quad \tilde{\boldsymbol{E}}=\frac{\partial W(\boldsymbol{F}, \tilde{\boldsymbol{D}})}{\partial \tilde{\boldsymbol{D}}} .
$$

Eq. (1) or (2) means that the form of $W(\boldsymbol{F}, \tilde{\boldsymbol{D}})$ determines the constitutive law of the dielectric elastomer.

A soft dielectric elastomer consists of long and flexible polymer chains with covalently bonded links. It is usually assumed that the elastomer can polarize nearly as freely as can liquids and so can be treated as an ideal dielectric elastomer (Zhao et al., 2007). That is, the electrical polarization of soft dielectrics is independent of their deformation. Then the free energy density of an ideal dielectric elastomer can be written as

$$
W(\boldsymbol{F}, \tilde{\boldsymbol{D}})=W_{s}(\boldsymbol{F})+W_{E}(\boldsymbol{F}, \tilde{\boldsymbol{D}}),
$$

where $W_{E}(\boldsymbol{F}, \tilde{\boldsymbol{D}})$ is expressed as (Zhao et al., 2007; Zhao and Wang, 2014):

$$
W_{E}(\boldsymbol{F}, \tilde{\boldsymbol{D}})=\frac{(\boldsymbol{F} \tilde{\boldsymbol{D}}) \cdot(\boldsymbol{F} \tilde{\boldsymbol{D}})}{2 \varepsilon \operatorname{det}(\boldsymbol{F})}=\frac{F_{i K} F_{i L}}{2 \varepsilon \operatorname{det}(\boldsymbol{F})} \tilde{D}_{K} \tilde{D}_{L}
$$

In Eq. (4), $\varepsilon$ is the permittivity of the dielectric, which is taken to be a constant independent of deformation (Suo, 2010). $W_{s}(\boldsymbol{F})$ is the free energy function for rubber-like (hyperelastic) materials.
Generally, for isotropic incompressible rubber-like materials, $W_{s}(\boldsymbol{F})$ is a function of $I_{1}$ and $I_{2}$, which are the first and second invariants of the right CauchyGreen deformation tensor $\boldsymbol{C}=\boldsymbol{F}^{\mathrm{T}} \boldsymbol{F}$, respectively.

For rubber-like materials such as a dielectric elastomer, constitutive models of rubber elasticity in the frameworks have been approached either through statistical mechanics or through continuum mechanics. The statistical mechanics approach is based on Gaussian and non-Gaussian statistics and long-chain molecular network theory. In a Gaussian treatment of a single chain, the Gaussian distribution is used to describe the end-to-end of the chain. The results are valid only when the stretch of the chain is limited, i.e., not approaching the limiting stretch. When the chain is highly extended, a non-Gaussian statistical treatment should be applied to obtain the properties of the network using Langevin chain statistics, including the three-chain model (Wang and Guth, 1952), the four-chain model (Flory and Rehner, 1943), the eight-chain model (Arruda and Boyce, 1993), and the full chain model ( $\mathrm{Wu}$ and van der Giessen, 1993). The continuum mechanics approach takes the rubber as a hyperelastic material with the deformation energy function dependent on the invariants of the stretch tensor. Thereafter, the MooneyRivilin model (Mooney, 1940), the Ogden model (Ogden, 1972), the Gent model (Gent, 1996), etc., have been developed to capture the stretch behavior of these kinds of materials. Treloar (1975) delivered a comprehensive review of the statistical description of rubber elasticity. Boyce and Arruda (2000) reviewed several constitutive models of incompressible rubber-like materials based on classic statistical mechanics and phenomenological theory (continuum mechanics). Marckmann and Verron (2006) compared 20 hyperelastic models of rubber-like materials. Both the material parameters and the stretch range of validity of each model were addressed. Horgan and Saccomandi (2006) reviewed the phenomenological hyperelastic constitutive models in respect of their limiting chain extensibility. Beda (2014) summarized the model-building strategies of hyperelastic constitutive models.

Table 1 lists some frequently-used stretching energy functions for analyzing incompressible dielectric elastomers. Fig. 2 shows the comparison of the nominal stress-stretch behavior of four frequently-used models (the neo-Hookean model, 
Table 1 Some frequently-used stretching energy functions for incompressible dielectric elastomers

\begin{tabular}{|c|c|c|c|c|c|}
\hline Model & Expression of $W_{s}$ & WLCE & NMP & Parameter & Type \\
\hline neo-Hookean (Treloar, 1943) & $W_{s}=\frac{\mu}{2}\left(I_{1}-3\right)$ & No & 1 & $\mu$ & A \\
\hline $\begin{array}{l}\text { Mooney-Rivlin (Mooney, 1940; } \\
\text { Rivlin, 1948) }\end{array}$ & $W_{s}=C_{1}\left(I_{1}-3\right)+C_{2}\left(I_{2}-3\right)$ & No & 2 & $C_{1}, C_{2}$ & B \\
\hline Ogden (Ogden, 1972) & $W_{s}=\sum_{i=1}^{N} \frac{\mu_{i}}{\alpha_{i}}\left(\lambda_{1}^{\alpha_{i}}+\lambda_{2}^{\alpha_{i}}+\lambda_{3}^{\alpha_{i}}-3\right)$ & Yes & $2 N$ & $\begin{array}{c}\mu_{i}, \alpha_{i} \\
(i=1,2, \ldots, N)\end{array}$ & B \\
\hline Yeoh (Yeoh, 1990) & $W_{s}=\sum_{i=1}^{3} C_{i}\left(I_{1}-3\right)^{i}$ & No & 3 & $C_{1}, C_{2}, C_{3}$ & B \\
\hline $\begin{array}{l}\text { Arruda-Boyce (Arruda and } \\
\text { Boyce, 1993) }\end{array}$ & $\begin{array}{l}W_{s}=\mu n\left[\frac{\beta_{c h} \lambda_{c h}}{\sqrt{n}}+\ln \left(\frac{\beta_{c h}}{\sinh \beta_{c h}}\right)\right], \\
\lambda_{c h}=\sqrt{\frac{I_{1}}{3}}=\sqrt{n}\left(\frac{1}{\tanh \beta_{c h}}-\frac{1}{\beta_{c h}}\right)\end{array}$ & Yes & 2 & $\mu, n$ & A \\
\hline Gent (Gent, 1996) & $W_{s}=-\frac{\mu}{2} J_{\lim } \ln \left(1-\frac{I_{1}-3}{J_{\lim }}\right)$ & Yes & 2 & $\mu, J_{\lim }$ & B \\
\hline
\end{tabular}

* Note: type A: classic statistical mechanics model; type B: phenomenological model; NMP: number of material parameters; WLCE: with limiting chain extensibility; $I_{1}$ and $I_{2}$ are the first and second invariants of the right Cauchy-Green deformation tensor

the Gent model, the Arruda-Boyce model, and the Ogden model with $N=3$ ) when subjected to uniaxial tension (Fig. 2a) and equibiaxial tension (Fig. 2b). The computational parameters are set as follows: in the Gent model, $J_{\lim }$ is set as $J_{\lim }=101$; in the ArrudaBoyce model, $n$ is set as $n=35$; in the Ogden model, the parameters are set as $N=3, \alpha_{1}=1.3, \alpha_{2}=5.0$, $\alpha_{3}=-2.0, \quad \mu_{1}=1.491 \mu, \mu_{2}=0.003 \mu$, and $\mu_{3}=-0.023 \mu$ (Liang and Cai, 2015).

There are also some other forms of $W_{s}(\boldsymbol{F})$ for incompressible rubber-like materials. For instance, Horgan and Saccomandi (2002) presented another constitutive model considering limiting chain extensibility. Horgan and Saccomandi (2005) obtained constitutive models for fiber-reinforced incompressible nonlinearly elastic solids. Guo et al. (2006) developed a composites-based hyperelastic constitutive model for soft materials. Hyperelastic models for incompressible fiber-reinforced elastomers were also proposed (Agoras et al., 2009; Fereidoonnezhad et al., 2013). A large-strain continuum mechanics framework for the development of constitutive models was presented by Danielsson et al. (2004). Huang (2014) presented a novel constitutive model for rubber-like materials with a deformation energy function including effects of both compressibility and temperature changes.
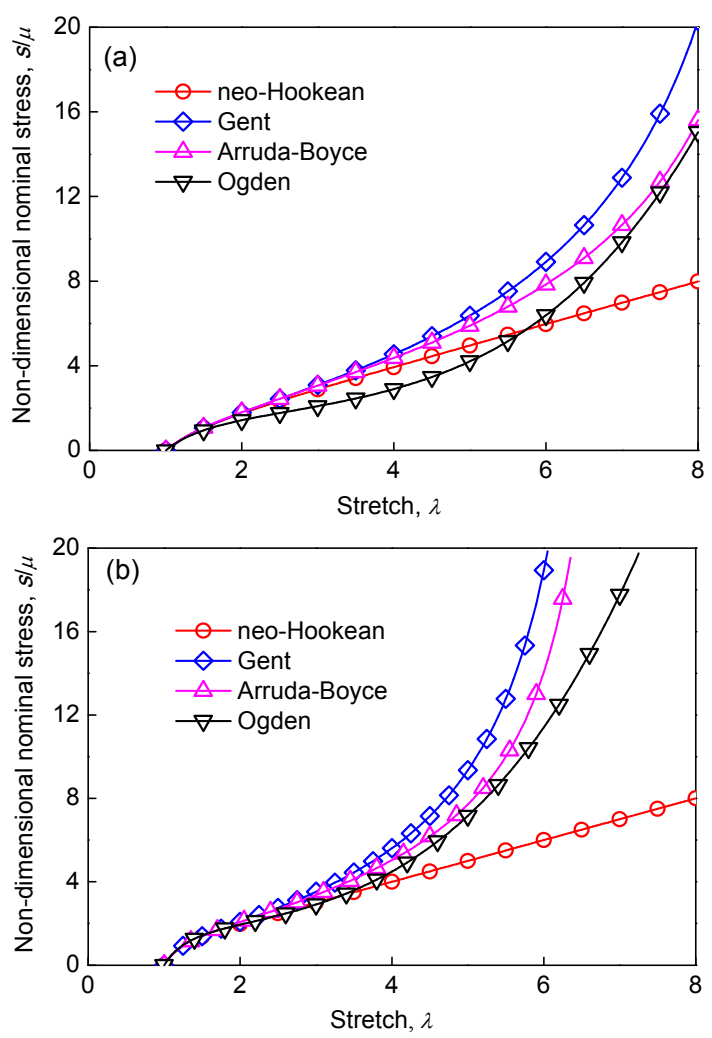

Fig. 2 Comparison of the nominal stress-stretch behavior of four frequently-used models, i.e., the neo-Hookean model, the Gent model, the Arruda-Boyce model, and the Ogden model with $N=3$

(a) Uniaxial tension; (b) Equibiaxial tension 
To model the electromechanical behaviors of dielectric elastomers in the context of engineering practice, some practical factors have also been considered, as shown in Table 2, such as compressibility (Tagarielli et al., 2012; Vertechy et al., 2012), polarization effect (Li B. et al., 2012; Liu et al., 2012; 2014b), unidirectional constraint (Huang et al., 2012b; Lu et al., 2012), variation of permittivity (Zhao and Suo, 2008a), thermally coupled (Liu et al., 2011; 2014c), hydrostatically coupled (Wang et al., 2012b), air coupled (Keplinger et al., 2012; Li et al., 2013), etc.

Furthermore, Yong et al. (2012) investigated electromechanical instability in incompressible dielectric elastomers by considering the effect of anisotropy. The free energy form was assumed to be the same as in Eq. (3) while the stretching energy function $W_{s}(\boldsymbol{F})$ was assumed to be a function of $I_{1}$, $I_{2}, I_{4}$, and $I_{5}$. Here $I_{4}=C_{12}^{2}+C_{13}^{2}$ and $I_{5}=C_{11}$. Siboni and Castañeda (2014) studied the finite-strain response and stability of fiber-constrained dielectric elastomer composites (DECs). The DECs consist of very long fibers, embedded firmly in an ideal dielectric matrix. Liu et al. (2015) investigated the effect of mass fraction of multi-walled carbon nanotubes on the stability of dielectric elastomer composites.

Based on Suo's theory (Suo et al., 2008; Suo 2010), the finite element method is able to study the dielectric elastomer structures with complicated configurations and/or loadings, and predict large

Table 2 Some special effects in modeling dielectric elastomers

\begin{tabular}{|c|c|}
\hline Factor & Key contribution or description \\
\hline Compressibility & $\begin{array}{l}\text { Another strain energy term } W_{b}(J) \text { is appended to the existing strain energy form: } \\
W(\boldsymbol{F}, \tilde{\boldsymbol{D}})=W_{s}(\boldsymbol{F})+W_{E}(\tilde{\boldsymbol{D}})+W_{b}(J), \quad W_{b}=-p(J-1+0.5 p / K) \text { (Vertechy et al., 2012) or } \\
W_{b}=0.5 K(J-1)^{2} \text { (Tagarielli et al., 2012), where } K \text { is the bulk modulus and } p \text { is the hydrostatic } \\
\text { pressure }\end{array}$ \\
\hline $\begin{array}{l}\text { Conditional } \\
\text { polarization }\end{array}$ & $\begin{array}{l}W_{E}(\tilde{\boldsymbol{D}})=\frac{\lambda_{1}^{-2} \lambda_{2}^{-2}}{2 \varepsilon\left(\lambda_{1}, \lambda_{2}\right)} \tilde{D}^{2}, \varepsilon=\varepsilon_{0}+\frac{N}{3 k T}\left[\phi\left(1+\Lambda^{-1}\right) \mu_{\mathrm{B}}^{2}+(1-\phi) \mu_{\mathrm{S}}^{2}\right], \\
\text { where } \varepsilon_{0} \text { is the permittivity of the vacuum and } N \text { is the number of molecules per unit volume. } \phi \text { is } \\
\text { the volumetric fraction of the backbone dipoles over the total monomer dipoles in a single chain. } \Lambda \\
\text { is a negative value representing the number of states that the dipoles may locate before polarization. } \\
\mu_{\mathrm{B}} \text { and } \mu_{\mathrm{S}} \text { are the dipolar moments of monomers in the backbone and in the side chains (Li B. et al., } \\
2012)\end{array}$ \\
\hline $\begin{array}{l}\text { Variation of } \\
\text { permittivity }\end{array}$ & $\begin{array}{l}W_{E}(\tilde{\boldsymbol{D}})=\frac{\lambda_{1}^{-1} \lambda_{2}^{-1} \lambda_{3}}{2 \varepsilon\left(\lambda_{1}, \lambda_{2}, \lambda_{3}\right)} \tilde{D}^{2}, \varepsilon=\varepsilon_{0}\left[1+a\left(\lambda_{3}-1\right)+b\left(\lambda_{1}+\lambda_{2}+\lambda_{3}-3\right)\right] \\
\text { where } \varepsilon_{0} \text { is the permittivity of the dielectric in the absence of deformation, and } a \text { and } b \text { are the coef- } \\
\text { ficients of electrostriction (Zhao and Suo, 2008a) }\end{array}$ \\
\hline $\begin{array}{r}\text { Thermally } \\
\text { coupled }\end{array}$ & $\begin{array}{l}W(\boldsymbol{F}, \tilde{\boldsymbol{D}}, T)=W_{s}(\boldsymbol{F}, T)+W_{E}(\tilde{\boldsymbol{D}}), \\
W_{s}(\boldsymbol{F}, T)=\frac{T}{2 T_{0}}\left[C_{1}\left(I_{1}-3\right)+C_{2}\left(I_{2}-3\right)\right]+c_{0}\left[\left(T-T_{0}\right)-T \ln \left(\frac{T}{T_{0}}\right)\right], \\
\text { where } T \text { is the current temperature and } T_{0} \text { is the reference temperature. } c_{0} \text { is the specific heat of } \\
\text { dielectric elastomers (Liu et al., 2011) }\end{array}$ \\
\hline $\begin{array}{l}\text { Unidirectional } \\
\text { constraint }\end{array}$ & $\begin{array}{l}\text { The dielectric elastomeric membrane contracts in the directions normal to the fibers, but keeps its } \\
\text { dimension in the direction along the fibers (Huang et al., 2012b; Lu et al., 2012) }\end{array}$ \\
\hline $\begin{array}{l}\text { Hydrostatically } \\
\text { coupled }\end{array}$ & $\begin{array}{l}\text { The fluid sealed between the active and passive membranes remains constant at a prescribed vol- } \\
\text { ume } 2 V_{0} \text {. That is, the confined fluid is taken to be incompressible. } V_{\text {act }}+V_{\text {pas }}=2 V_{0} \text { (Wang et al., } \\
\text { 2012b) }\end{array}$ \\
\hline Air coupled & $\begin{array}{l}\text { The air enclosed in the chamber and bubble obeys the ideal-gas law: } \\
\left(p+p_{\text {atm }}\right)\left(V+V_{\mathrm{c}}\right)=\left(p_{0}+p_{\text {atm }}\right)\left(V_{0}+V_{\mathrm{c}}\right) \text {. } \\
\text { Here } p+p_{\text {atm }} \text { and } V+V_{\mathrm{c}} \text { are the pressure and volume in the current state; } p_{0}+p_{\text {atm }} \text { and } V_{0}+V_{\mathrm{c}} \text { are those } \\
\text { quantities in the reference state. } p_{\text {atm }} \text { is the atmosphere pressure and } V_{\mathrm{c}} \text { is the volume of the chamber } \\
\text { (Keplinger } \text { et al., 2012; Li et al., 2013) }\end{array}$ \\
\hline
\end{tabular}


deformation and electromechanical instability behaviors. Zhao and Suo (2008b) implemented a user subroutine (UMAT) in the commercial finite element software ABAQUS, using the neo-Hookean model. This UMAT is powerful for analyzing dielectric elastomer transducers undergoing inhomogeneous deformation. Qu and Suo (2012) adopted the same framework to develop a finite element method implemented in ABAQUS by defining two sets of elements on one set of nodes, with each set of elements used for either mechanical deformation or electric induced deformation. This superposition-like method can use any material mechanical model in ABAQUS. Klinkel et al. (2013) developed a solid shell finite element formulation to investigate the electromechanical behavior of thin dielectric elastomer structures. Recently, Wang et al. (2014) used a nonlinear, dynamic finite element model with a finite deformation viscoelastic constitutive law to study the inhomogeneous deformation and instabilities of dielectric elastomers subjected to a constant voltage.

\subsection{Visco-hyperelastic model of dielectric elastomer}

Some experiments show that the response of a dielectric elastomer is time-dependent and dissipative when subjected to force or voltage (Wissler and Mazza, 2005; 2007; Plante and Dubowsky, 2006; Qu et al., 2012; Tagarielli et al., 2012; Li et al., 2013; Liu L. et al., 2014). This behavior results from the slippage between the long polymers and the rotation of joints between monomers (Suo, 2010).

Guided by non-equilibrium thermodynamics, the following inequality can be obtained (Suo, 2010; Zhao et al., 2011):

$$
\boldsymbol{s} \delta \boldsymbol{F}+\tilde{\boldsymbol{E}} \delta \tilde{\boldsymbol{D}} \leq \delta W\left(\boldsymbol{F}, \tilde{\boldsymbol{D}}, \xi_{1}, \xi_{2}, \ldots\right),
$$

where $\xi_{1}, \xi_{2}, \ldots$ are known as internal variables. If we assume the system is in mechanical and electrostatic equilibrium, then Eq. (5) can be rewritten as

$$
\boldsymbol{s}=\frac{\partial W(\boldsymbol{F}, \tilde{\boldsymbol{D}})}{\partial \boldsymbol{F}}, \quad \tilde{\boldsymbol{E}}=\frac{\partial W(\boldsymbol{F}, \tilde{\boldsymbol{D}})}{\partial \tilde{\boldsymbol{D}}}, \quad \sum_{i} \frac{\partial W}{\partial \xi_{i}} \delta \xi_{i} \leq 0 .
$$

The inequality in Eq. (6) may be satisfied by adopting a suitable kinetic mode of the type:

$$
\frac{\mathrm{d} \xi_{i}}{\mathrm{~d} t}=-\sum_{j} M_{i j} \frac{\partial W\left(\boldsymbol{F}, \tilde{\boldsymbol{D}}, \xi_{1}, \xi_{2}, \ldots\right)}{\partial \xi_{j}},
$$

where $\boldsymbol{M}$ is a positive-definite matrix.

The total free energy function can be treated as (Hong, 2011; Park and Nguyen, 2013)

$$
W\left(\boldsymbol{F}, \tilde{\boldsymbol{D}}, \xi_{1}, \xi_{2}, \ldots\right)=W_{\mathrm{EQ}}(\boldsymbol{F}, \tilde{\boldsymbol{D}})+W_{\mathrm{NEQ}}\left(\boldsymbol{F}, \xi_{1}, \xi_{2}, \ldots\right),
$$

where $W_{\mathrm{EQ}}(\boldsymbol{F}, \tilde{\boldsymbol{D}})$ is named as the equilibrium Helmholtz free-energy in the local equilibrium state and takes the form $W_{s}(\boldsymbol{F}, \tilde{\boldsymbol{D}})$ for hyperelastic dielectric elastomers. $W_{\mathrm{NEQ}}\left(\boldsymbol{F}, \xi_{1}, \xi_{2}, \ldots\right)$ is the nonequilibrium Helmholtz free energy and is used to describe the dissipative process. Some specific models have been presented in the open literature (Foo et al., 2012a; 2012b; Li T.F. et al., 2012; Wang et al., 2013; Bai et al., 2014). For an incompressible dielectric elastomer thin membrane subjected to a voltage between the two compliant electrodes, Foo et al. (2012a) constructed a specific viscoelastic model by using two parallel units. One unit consists of a spring $\alpha$ and the other unit consists of a spring $\beta$ and a dashpot. Let $\lambda_{1}$ and $\lambda_{2}$ be the stretches of the elastomer of spring $\alpha$ and $\xi_{1}$ and $\xi_{2}$ be stretches in the dashpot. By employing the Gent model (Gent, 1996), they obtained:

$$
\left\{\begin{array}{c}
\sigma_{1}=-\varepsilon E^{2}+\frac{\mu_{\alpha}\left(\lambda_{1}^{2}-\lambda_{1}^{-2} \lambda_{2}^{-2}\right)}{1-\left(\lambda_{1}^{2}+\lambda_{2}^{2}+\lambda_{1}^{-2} \lambda_{2}^{-2}-3\right) / J_{\alpha}^{\lim }} \\
+\frac{\mu_{\beta}\left(\lambda_{1}^{2} \xi_{1}^{-2}-\xi_{1}^{2} \xi_{2}^{2} \lambda_{1}^{-2} \lambda_{2}^{-2}\right)}{1-\left(\lambda_{1}^{2} \xi_{1}^{-2}+\lambda_{2}^{2} \xi_{2}^{-2}+\xi_{1}^{2} \xi_{2}^{2} \lambda_{1}^{-2} \lambda_{2}^{-2}-3\right) / J_{\beta}^{\lim }}, \\
\sigma_{2}=-\varepsilon E^{2}+\frac{\mu_{\alpha}\left(\lambda_{2}^{2}-\lambda_{1}^{-2} \lambda_{2}^{-2}\right)}{1-\left(\lambda_{1}^{2}+\lambda_{2}^{2}+\lambda_{1}^{-2} \lambda_{2}^{-2}-3\right) / J_{\alpha}^{\lim }} \\
+\frac{\mu_{\beta}\left(\lambda_{2}^{2} \xi_{2}^{-2}-\xi_{1}^{2} \xi_{2}^{2} \lambda_{1}^{-2} \lambda_{2}^{-2}\right)}{1-\left(\lambda_{1}^{2} \xi_{1}^{-2}+\lambda_{2}^{2} \xi_{2}^{-2}+\xi_{1}^{2} \xi_{2}^{2} \lambda_{1}^{-2} \lambda_{2}^{-2}-3\right) / J_{\beta}^{\lim }},
\end{array}\right.
$$

where $\mu_{\alpha}$ and $\mu_{\beta}$ are the shear moduli of the two springs, and $J_{\alpha}^{\mathrm{lim}}$ and $J_{\beta}^{\mathrm{lim}}$ are the constants related to the limiting stretches of the two springs. $\sigma_{1}$ and $\sigma_{2}$ are the true stresses and $E$ is the true electric field. They further modeled the dashpot as a Newtonian fluid and the corresponding evolution equations were obtained: 


$$
\left\{\begin{aligned}
\frac{\mathrm{d} \xi_{1}}{\mathrm{~d} t}= & \frac{\xi_{1}}{3 \eta} \times\left[\frac{\mu_{\beta}\left(\lambda_{1}^{2} \xi_{1}^{-2}-\xi_{1}^{2} \xi_{2}^{2} \lambda_{1}^{-2} \lambda_{2}^{-2}\right)}{1-\left(\lambda_{1}^{2} \xi_{1}^{-2}+\lambda_{2}^{2} \xi_{2}^{-2}+\xi_{1}^{2} \xi_{2}^{2} \lambda_{1}^{-2} \lambda_{2}^{-2}-3\right) / J_{\beta}^{\mathrm{lim}}}\right. \\
& \left.-\frac{\mu_{\beta}\left(\lambda_{2}^{2} \xi_{2}^{-2}-\xi_{1}^{2} \xi_{2}^{2} \lambda_{1}^{-2} \lambda_{2}^{-2}\right) / 2}{1-\left(\lambda_{1}^{2} \xi_{1}^{-2}+\lambda_{2}^{2} \xi_{2}^{-2}+\xi_{1}^{2} \xi_{2}^{2} \lambda_{1}^{-2} \lambda_{2}^{-2}-3\right) / J_{\beta}^{\mathrm{lim}}}\right], \\
\frac{\mathrm{d} \xi_{2}}{\mathrm{~d} t=} & \frac{\xi_{2}}{3 \eta} \times\left[\frac{\mu_{\beta}\left(\lambda_{2}^{2} \xi_{2}^{-2}-\xi_{1}^{2} \xi_{2}^{2} \lambda_{1}^{-2} \lambda_{2}^{-2}\right)}{1-\left(\lambda_{1}^{2} \xi_{1}^{-2}+\lambda_{2}^{2} \xi_{2}^{-2}+\xi_{1}^{2} \xi_{2}^{2} \lambda_{1}^{-2} \lambda_{2}^{-2}-3\right) / J_{\beta}^{\mathrm{lim}}}\right. \\
& \left.-\frac{\mu_{\beta}\left(\lambda_{1}^{2} \xi_{1}^{-2}-\xi_{1}^{2} \xi_{2}^{2} \lambda_{1}^{-2} \lambda_{2}^{-2}\right) / 2}{1-\left(\lambda_{1}^{2} \xi_{1}^{-2}+\lambda_{2}^{2} \xi_{2}^{-2}+\xi_{1}^{2} \xi_{2}^{2} \lambda_{1}^{-2} \lambda_{2}^{-2}-3\right) / J_{\beta}^{\mathrm{lim}}}\right],
\end{aligned}\right.
$$

where $\eta$ is the viscosity of the dashpot.

Foo et al. (2012a) also presented a model of leakage current. In that model, the dielectric elastomer was considered as a capacitor with a resistor in parallel. Based on the Kelvin-Voigt model, a viscohyperelastic model was proposed by Lochmatter et al. (2007) by fitting the uniaxial tensile-creeprelaxation test data of acrylic VHB 4910 film.

\section{Constitutive models of responsive gel}

A cross-linked polymer can take up the solvent molecules from the surrounding environment and form a gel. Fig. 3 illustrates the schematics and photos of a responsive gel in dry and swollen states.

(a)

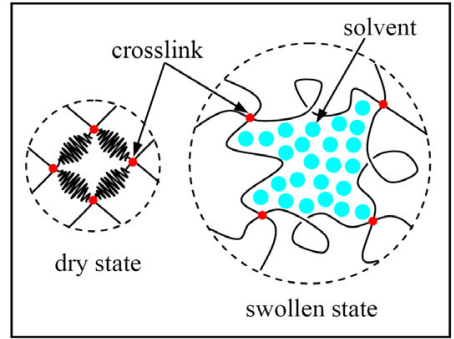

(b)

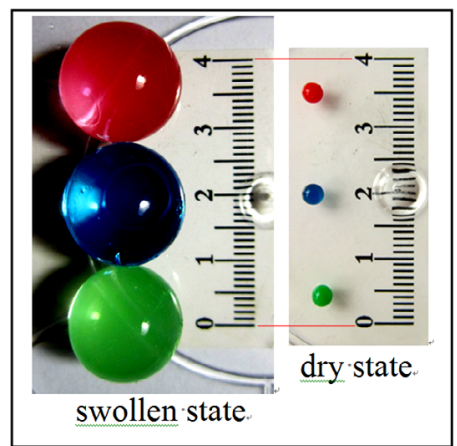

Fig. 3 Schematics (a) and photos (b) of a responsive gel
The stimuli of the responsive gels can be temperature, $\mathrm{pH}$, light, electric field humidity, stress, etc. (Gerlach et al., 2005; Yamaue and Doi, 2005; Lawrence et al., 2007; Rotzetter et al., 2012; Zarzar et al., 2012; Chu et al., 2013; Wang et al., 2013; Lim et al., 2014). Hong et al. (2008) presented a framework of coupled diffusion and large deformation in polymeric gels. Based on non-equilibrium thermodynamic theory, one can obtain (Hong et al., 2008; Toh et al., 2013):

$$
\boldsymbol{s}=\frac{\partial W(\boldsymbol{F}, C)}{\partial \boldsymbol{F}}, \quad \mu=\frac{\partial W(\boldsymbol{F}, C)}{\partial C} .
$$

It should be specially mentioned that in this section, $\mu$ denotes the chemical potential and $C$ is the concentration of the solvent. $W(\boldsymbol{F}, C)$ is the free energy of the polymeric gel. Following the treatment introduced by Flory and Rehner (1943), $W(\boldsymbol{F}, C)$ takes the form:

$$
W(\boldsymbol{F}, C)=W_{s}(\boldsymbol{F})+W_{m}(C),
$$

where $W_{s}(\boldsymbol{F})$ and $W_{m}(C)$ are the free energy functions of stretching and mixing, respectively, and can be written as (Hong et al., 2008; 2009)

$$
\begin{aligned}
& W_{s}(\boldsymbol{F})=0.5 N k T\left[\lambda_{1}^{2}+\lambda_{2}^{2}+\lambda_{3}^{2}-3-2 \log \left(\lambda_{1} \lambda_{2} \lambda_{3}\right)\right], \\
& W_{m}(C)=-\frac{k T}{\Omega}\left[\Omega C \log \left(1+\frac{1}{\Omega C}\right)+\frac{\chi}{1+\Omega C}\right]
\end{aligned}
$$

where $\chi$ is a dimensionless measure of mixing enthalpy. The product $k T$ is the temperature in the unit of energy. $N$ is the number of the polymeric chain divided by the volume of the dry network and $\Omega$ is the volume of a solvent molecule. The condition of molecular incompressibility demands:

$$
1+\Omega C=\lambda_{1} \lambda_{2} \lambda_{3}
$$

That is, the free energy function (12) should be enforced by the constraint (14). By using the Legendre transformation:

$$
\tilde{W}(\boldsymbol{F}, \mu)=W(\boldsymbol{F}, C)-\mu C,
$$

we have (Hong et al., 2009; Toh et al., 2013): 


$$
\boldsymbol{s}=\frac{\partial \tilde{W}(\boldsymbol{F}, \mu)}{\partial \boldsymbol{F}}, \quad C=-\frac{\partial \tilde{W}(\boldsymbol{F}, \mu)}{\partial \mu} .
$$

Utilizing Eqs. (12)-(14), Eq. (15) can be specified as

$$
\begin{aligned}
\tilde{W}(\boldsymbol{F}, \mu) & =\frac{1}{2} N k T\left[\lambda_{1}^{2}+\lambda_{2}^{2}+\lambda_{3}^{2}-3-2 \log \left(\lambda_{1} \lambda_{2} \lambda_{3}\right)\right] \\
- & \frac{k T}{\Omega}\left[\left(\lambda_{1} \lambda_{2} \lambda_{3}-1\right) \log \left(\frac{\lambda_{1} \lambda_{2} \lambda_{3}}{\lambda_{1} \lambda_{2} \lambda_{3}-1}\right)+\frac{\chi}{\lambda_{1} \lambda_{2} \lambda_{3}}\right] \\
- & \frac{\mu}{\Omega}\left(\lambda_{1} \lambda_{2} \lambda_{3}-1\right) .
\end{aligned}
$$

Based on the framework presented by Hong et al. (2008), some models for special cases have been constructed. The inhomogeneous and anisotropic equilibrium state of a swollen hydrogel containing a hard core has been solved by Zhao et al. (2008). Hong et al. (2009) also presented the model for inhomogeneous swelling of a gel in equilibrium with a solvent and mechanical load. Wu and Zhong (2013) simulated the inhomogeneous equilibrium swelling of core-shell-coating gels. Dai and Song (2011) obtained some analytical solutions of the equilibrium states of a swollen hydrogel shell under spherical deformation by the perturbation method. Chen and Dai (2013) obtained the asymptotic solutions of cylinder and core-shell polymer gels for the equilibrium states. Cai et al. (2010) investigated the kinetic swelling process of a polymeric tube. Cai and Suo (2012) presented the equations of state for ideal elastomeric gels. Cai and Suo (2011) dealt with the mechanics and chemical thermodynamics of phase transition in temperature-sensitive hydrogels. In their model, $W_{s}(\boldsymbol{F})$ also takes the form as in Eq. (13), while $W_{m}(C)$ is modified as (Cai and Suo, 2011)

$$
W_{m}(C)=\frac{k T}{\Omega}\left[\Omega C \log \left(\frac{\Omega C}{1+\Omega C}\right)+\frac{\chi \Omega C}{1+\Omega C}\right],
$$

with

$$
\begin{aligned}
& \chi(T, \phi)=\chi_{0}+\chi_{1} \phi, \\
& \chi_{0}=A_{0}+B_{0} T, \quad \chi_{1}=A_{1}+B_{1} T, \\
& \phi=(1+\Omega C)^{-1} .
\end{aligned}
$$

For PNIPAM-water solutions, Afroze et al. (2000) fitted their experimental data by using the following parameters:

$$
\begin{aligned}
& A_{0}=-12.97, \quad B_{0}=0.04496 K^{-1}, \\
& A_{1}=-17.92, \quad B_{1}=-0.0569 K^{-1} .
\end{aligned}
$$

Hong et al. (2010) developed a model for large deformation and electrochemistry of polyelectrolyte gels when immersed in ionic solution. In this model, the free energy is treated as

$$
W=W_{\text {net }}+W_{\text {sol }}+W_{\text {ion }}+W_{\text {pol }}
$$

where $W_{\text {net }}, W_{\text {sol }}, W_{\text {ion }}$, and $W_{\text {pol }}$ are the free energy functions due to stretching the network, mixing the solvent with the polymers, mixing the ions with the solvent, and polarizing the gel. The specific form of each term has been presented in Hong et al. (2010). Then the constitutive model for polyelectrolyte gels can be obtained:

$$
\begin{aligned}
& \boldsymbol{s}=\frac{\partial W\left(\boldsymbol{F}, \tilde{\boldsymbol{D}}, C^{1}, C^{2}, \ldots\right)}{\partial \boldsymbol{F}}, \quad \tilde{\boldsymbol{E}}=\frac{\partial W\left(\boldsymbol{F}, \tilde{\boldsymbol{D}}, C^{1}, C^{2}, \ldots\right)}{\partial \tilde{\boldsymbol{D}}}, \\
& \mu^{\alpha}=e z^{\alpha} \boldsymbol{\Phi}+\frac{\partial W\left(\boldsymbol{F}, \tilde{\boldsymbol{D}}, C^{1}, C^{2}, \ldots\right)}{\partial C^{\alpha}} \quad(\alpha=1,2, \ldots),
\end{aligned}
$$

where $e$ is the elementary charge, $z^{\alpha}$ is the valence of species $\alpha$, and $\Phi$ is the electric potential.

A theory of constrained swelling of a $\mathrm{pH}$ sensitive hydrogel was developed by Marcombe et al. (2010). The free energy function accounting for the stretching of the network $W_{\text {net }}$, mixing of the network with the solution $W_{\text {sol }}$, mixing the ions with the solvent $W_{\text {ion }}$, and dissociating the acidic groups $W_{\text {dis }}$ is shown below as (Marcombe et al., 2010; Toh et al., 2014)

$$
W=W_{\text {net }}+W_{\text {sol }}+W_{\text {ion }}+W_{\text {dis }} .
$$

The constitutive model was also specified by Marcombe et al. (2010).

Yamaue and Doi (2004) proposed a linearized stress-diffusion coupling model for the 1D swelling dynamics of polymer gels. The constitutive equation involves the bulk modulus and the shear modulus of gels. Based on the stress-diffusion model, Lucantonio and Nardinocchi (2012) presented a reduced model of swelling-induced bending of gel bars under the assumption of plane stress. In response to the 
stimuli, the elastomeric gels show both viscoelasticity and poroelasticity. Hu and Suo (2012) developed a theory of concurrent viscoelasticity and poroelasticity. The kinetics of viscoelasticity are described by using the homogeneous states of a material element, while the kinetics of poroelasticity are described by using the inhomogeneous states in a body.

Reactive gels have also been investigated. Boissonade $(2003 ; 2009)$ presented the chemical reaction-diffusion models to simulate the selfoscillation of gels. Due to the swelling-deswelling process, the gel can switch between "reacted state" and "unreacted state" which leads to temporal shape changes. Yashin and Balazs (2006) and Kuksenok et al. (2008) developed models for the polymer gels involved in the Belousov-Zhabotinsky (BZ) reaction. Yashin et al. (2012) reviewed the coupling models between non-linear chemical dynamics and mechanics for reactive gels.

\section{Conclusions}

The constitutive models of artificial muscles have been developed and widely used in analyzing the electromechanical or chemomechanical behaviors of dielectric elastomer and gel based actuators, sensors, energy harvesters, soft robots, and soft tissues, etc. The constitutive models are an important foundation for predicting and improving the performance of artificial muscles.

The constitutive models of artificial muscles are complicated due to the large deformation and the multi-field coupling effect. Based on equilibrium and non-equilibrium thermodynamics, the constitutive models of dielectric elastomers and responsive gels can be effectively constructed by using free energy functions. In the models presented, the material parameters can be determined by fitting to the experimental data.

There are a number of constitutive models for rubber-like materials. It is important to select a suitable model for theoretical analysis of soft materials.

\section{References}

Afroze, F., Nies, E., Berghmans, H., 2000. Phase transitions in the system $\operatorname{poly}(N$-isopropylacrylamide $) /$ water and swelling behavior of the corresponding networks. Journal of Molecular Structure, 554(1):55-68. http://dx.doi.org/10.1016/S0022-2860(00)00559-7
Agoras, M., Lopez-Pamies, O., Castañeda, P.P., 2009. A general hyperelastic model for incompressible fiberreinforced elastomers. Journal of the Mechanics and Physics of Solids, 57(2):268-286. http://dx.doi.org/10.1016/j.jmps.2008.10.014

Ahnert, K., Abel, M., Kollosche, M., et al., 2011. Soft capacitors for wave energy harvesting. Journal of Materials Chemistry, 21(38):14492-14497. http://dx.doi.org/10.1039/c1jm12454d

Akbari, S., Shea, H.R., 2012. Microfabrication and characterization of an array of dielectric elastomer actuators generating uniaxial strain to stretch individual cells. Journal of Micromechanics and Microengineering, 22(4):045020. http://dx.doi.org/10.1088/0960-1317/22/4/045020

Arruda, E.M., Boyce, M.C., 1993. A three-dimensional constitutive model for the large strech behavior of rubber elastic materials. Journal of the Mechanics and Physics of Solids, 41(2):389-412. http://dx.doi.org/10.1016/0022-5096(93)90013-6

Aschwanden, M., Stemmer, A., 2006. Polymeric, electrically tunable diffraction grating based on artificial muscles. Optics Letters, 31(17):2610-2612. http://dx.doi.org/10.1364/OL.31.002610

Aw, K.C., McDaid, A.J., 2014. Bio-applications of ionic polymer metal composite transducers. Smart Materials and Structures, 23(7):074005.

Bai, Y.Y., Jiang, Y.H., Chen, B.H., et al., 2014. Cyclic performance of viscoelastic dielectric elastomers with solid hydrogel electrodes. Applied Physics Letters, 104(6):062902. http://dx.doi.org/10.1063/1.4865200

Balasubramanian, R., Santos, V.J., 2014. The Human Hand as an Inspiration for Robot Hand Development. Springer, Heidelberg.

Bassil, M., Davenas, J., Tahchi, M.E., 2008. Electrochemical properties and actuation mechanisms of polyacrylamide hydrogel for artificial muscle application. Sensors and Actuators B: Chemical, 134(2):496-501. http://dx.doi.org/10.1016/j.snb.2008.05.025

Beda, T., 2014. An approach for hyperelastic model-building and parameters estimation: a review of constitutive models. European Polymer Journal, 50:97-108. http://dx.doi.org/10.1016/j.eurpolymj.2013.10.006

Biddiss, E., Chau, T., 2008. Dielectric elastomers as actuators for upper limb prosthetics: challenges and opportunities. Medical Engineering \& Physics, 30(4):403-418. http://dx.doi.org/10.1016/j.medengphy.2007.05.011

Boissonade, J., 2003. Simple chemomechanical process for self-generation of rhythms and forms. Physical Review Letters, 90(18): 188302. http://dx.doi.org/10.1103/PhysRevLett.90.188302

Boissonade, J., 2009. Oscillatory dynamics induced in polyelectrolyte gels by a non-oscillatory reaction: a model. European Physical Journal E, 28(3):337-346. http://dx.doi.org/10.1140/epje/i2008-10425-1 
Boyce, M.C., Arruda, E.M., 2000. Constitutive models of rubber elasticity: a review. Rubber Chemistry and Technology, 73(3):504-523. http://dx.doi.org/10.5254/1.3547602

Cai, S.Q., Suo, Z.G., 2011. Mechanics and chemical thermodynamics of phase transition in temperaturesensitive hydrogels. Journal of the Mechanics and Physics of Solids, 59(11):2259-2278. http://dx.doi.org/10.1016/j.jmps.2011.08.008

Cai, S.Q., Suo, Z.G., 2012. Equations of state for ideal elastomeric gels. Europhysics Letters, 97(3):34009. http://dx.doi.org/10.1209/0295-5075/97/34009

Cai, S.Q., Lou, Y.C., Ganguly, P., et al., 2010. Force generated by a swelling elastomer subject to constraint. Journal of Applied Physics, 107(10):103535. http://dx.doi.org/10.1063/1.3428461

Carpi, F., Rossi, D.D., 2004. Dielectric elastomer cylindrical actuators: electromechanical modelling and experimental evaluation. Materials Science and Engineering: $C$, 24(4):555-562. http://dx.doi.org/10.1016/j.msec.2004.02.005

Carpi, F., Migliore, A., Serra, G., et al., 2005. Helical dielectric elastomer actuators. Smart Materials and Structures, 14(6): 1210-1216.

Carpi, F., Salaris, C., Rossi, D.D., 2007. Folded dielectric elastomer actuators. Smart Materials and Structures, 16(2):S300-S305.

Carpi, F., Frediani, G., Rossi, D.D., 2010. Hydrostatically coupled dielectric elastomer actuators. IEEE/ASME Transactions on Mechatronics, 15(2):308-315. http://dx.doi.org/10.1109/TMECH.2009.2021651

Carpi, F., Kornbluh, R., Sommer-Larsen, P., et al., $2011 \mathrm{a}$. Electroactive polymer actuators as artificial muscles: are they ready for bioinspired applications? Bioinspiration \& Biomimetics, 6(4):045006.

Carpi, F., Frediani, G., Turco, S., et al., 2011b. Bioinspired tunable lens with muscle-like electroactive elastomers. Advanced Functional Materials, 21(21):4152-4158. http://dx.doi.org/10.1002/adfm.201101253

Chen, X.Y., Dai, H.H., 2013. Asymptotic solutions and new insights for cylinder and core-shell polymer gels in a solvent. Soft Matter, 9(36):8664-8677. http://dx.doi.org/10.1039/c3sm50674f

Chiba, S., Waki, M., Wada, T., et al., 2013. Consistent ocean wave energy harvesting using electroactive polymer (dielectric elastomer) artificial muscle generators. Applied Energy, 104:497-502.

http://dx.doi.org/10.1016/j.apenergy.2012.10.052

Chu, L.Y., Xie, R., Ju, X.J., et al., 2013. Smart Hydrogel Functional Material. Springer, Heidelberg.

Dai, H.H., Song, Z.L., 2011. Some analytical formulas for the equilibrium states of a swollen hydrogel shell. Soft Matter, 7(18):8473-8483. http://dx.doi.org/10.1039/c1sm05425b

Danielsson, M., Parks, D.M., Boyce, M.C., 2004. Constitutive modeling of porous hyperelastic materials. Mechanics of Materials, 36(4):347-358.
http://dx.doi.org/10.1016/S0167-6636(03)00064-4

Fang, Z.H., Punckt, C., Leung, E.Y., et al., 2010. Tuning of structural color using a dielectric actuator and multifunctional compliant electrodes. Applied Optics, 49(35): 6689-6696.

http://dx.doi.org/10.1364/AO.49.006689

Fereidoonnezhad, B., Naghdabadi, R., Arghavani, J., 2013. A hyperelastic constitutive model for fiber-reinforced rubber-like materials. International Journal of Engineering Science, 71:36-44. http://dx.doi.org/10.1016/j.ijengsci.2013.06.001

Flory, P.J., Rehner, J., 1943. Statistical mechanics of crosslinked polymer networks. II. Swelling. Journal of Chemical Physics, 11(11):521-526. http://dx.doi.org/10.1063/1.1723792

Foo, C.C., Cai, S.Q., Koh, S.J.A., et al., 2012a. Model of dissipative dielectric elastomers. Journal of Applied Physics, 111(3):034102. http://dx.doi.org/10.1063/1.3680878

Foo, C.C., Koh, S.J.A., Keplinger, C., et al., 2012b. Performance of dissipative dielectric elastomer generators. Journal of Applied Physics, 111(9):094107. http://dx.doi.org/10.1063/1.4714557

Gent, A.N., 1996. A new constitutive relation for rubber. Rubber Chemistry and Technology, 69(1):59-61. http://dx.doi.org/10.5254/1.3538357

Gerlach, G., Guenther, M., Sorber, J., et al., 2005. Chemical and $\mathrm{pH}$ sensors based on the swelling behavior of hydrogels. Sensors and Actuators B: Chemical, 111112:555-561. http://dx.doi.org/10.1016/j.snb.2005.03.040

Giousouf, M., Kovacs, G., 2013. Dielectric elastomer actuators used for pneumatic valve technology. Smart Materials and Structures, 22(10):104010.

Gisby, T.A., O’Brien, B.M., Anderson, I.A., 2013. Self sensing feedback for dielectric elastomer actuators. Applied Physics Letters, 102(19):193703. http://dx.doi.org/10.1063/1.4805352

Graf, C., Hitzbleck, J., Feller, T., et al., 2014. Dielectric elastomer-based energy harvesting: material, generator design, and optimization. Journal of Intelligent Material Systems and Structures, 25(8):951-966. http://dx.doi.org/10.1177/1045389X13502857

Guo, Z.Y., Peng, X.Q., Moran, B., 2006. A composites-based hyperelastic constitutive model for soft tissue with application to the human annulus fibrosus. Journal of the Mechanics and Physics of Solids, 54(9):1952-1971. http://dx.doi.org/10.1016/j.jmps.2006.02.006

Haus, H., Matysek, M., Moßinger, H., et al., 2013. Modelling and characterization of dielectric elastomer stack actuators. Smart Materials and Structures, 22(10): 104009.

Hong, W., 2011. Modeling viscoelastic dielectrics. Journal of the Mechanics and Physics of Solids, 59(3):637-650. http://dx.doi.org/10.1016/j.jmps.2010.12.003

Hong, W., Zhao, X.H., Zhou, J.X., et al., 2008. A theory of coupled diffusion and large deformation in polymeric 
gels. Journal of the Mechanics and Physics of Solids, 56(5):1779-1793.

http://dx.doi.org/10.1016/j.jmps.2007.11.010

Hong, W., Liu, Z.S., Suo, Z.G., 2009. Inhomogeneous swelling of a gel in equilibrium with a solvent and mechanical load. International Journal of Solids and Structures, 46(17):3282-3289.

http://dx.doi.org/10.1016/j.ijsolstr.2009.04.022

Hong, W., Zhao, X.H., Suo, Z.G., 2010. Large deformation and electrochemistry of polyelectrolyte gels. Journal of the Mechanics and Physics of Solids, 58(4):558-577. http://dx.doi.org/10.1016/j.jmps.2010.01.005

Horgan, C.O., Saccomandi, G., 2002. Constitutive modelling of rubber-like and biological materials with limiting chain extensibility. Mathematics and Mechanics of Solids, 7(4):353-371. http://dx.doi.org/10.1177/108128028477

Horgan, C.O., Saccomandi, G., 2005. A new constitutive theory for fiber-reinforced incompressible nonlinearly elastic solids. Journal of the Mechanics and Physics of Solids, 53(9): 1985-2015. http://dx.doi.org/10.1016/j.jmps.2005.04.004

Horgan, C.O., Saccomandi, G., 2006. Phenomenological hyperelastic strain-stiffening constitutive models for rubber. Rubber Chemistry and Technology, 79(1):152169.

http://dx.doi.org/10.5254/1.3547924

Hu, Y.H., Suo, Z.G., 2012. Viscoelasticity and poroelasticity in elastomeric gels. Acta Mechanica Solida Sinica, 25(5): 441-458.

http://dx.doi.org/10.1016/S0894-9166(12)60039-1

Huang, J.S., Li, T.F, Foo, C.C., et al., 2012a. Giant, voltageactuated deformation of a dielectric elastomer under dead load. Applied Physics Letters, 100(4):041911. http://dx.doi.org/10.1063/1.3680591

Huang, J.S., Lu, T.Q., Zhu, J., et al., 2012b. Large, unidirectional actuation in dielectric elastomers achieved by fiber stiffening. Applied Physics Letters, 100(21): 211901 http://dx.doi.org/10.1063/1.4720181

Huang, J.S., Shian, S., Suo, Z.G., et al., 2013. Maximizing the energy density of dielectric elastomer generators using equi-biaxial loading. Advanced Functional Materials, 23(40):5056-5061. http://dx.doi.org/10.1002/adfm.201300402

Huang, Z.P., 2014. A novel constitutive formulation for rubberlike materials in thermoelasticity. Journal of Applied Mechanics, 81(4):041013. http://dx.doi.org/10.1115/1.4025272

Hunt, S., McKay, T.G., Anderson, I.A., 2014. A self-healing dielectric elastomer actuator. Applied Physics Letters, 104(11): 113701 . http://dx.doi.org/10.1063/1.4869294

Joglekar, M.M., 2014. An energy-based approach to extract the dynamic instability parameters of dielectric elastomer actuators. Journal of Applied Mechanics, 81(9): 091010 . http://dx.doi.org/10.1115/1.4027925

Jung, K., Kim, K.J., Choi, H.R., 2008. A self-sensing dielectric elastomer actuator. Sensors and Actuators A: Physical, 143(2):343-351. http://dx.doi.org/10.1016/j.sna.2007.10.076

Kaltseis, R., Keplinger, C., Baumgartner, R., et al., 2011. Method for measuring energy generation and efficiency of dielectric elastomer generators. Applied Physics Letters, 99(16): 162904. http://dx.doi.org/10.1063/1.3653239

Keplinger, C., Li, T.F., Baumgartner, R., et al., 2012. Harnessing snap-through instability in soft dielectrics to achieve giant voltage-triggered deformation. Soft Matter, 8(2):285-288. http://dx.doi.org/10.1039/C1SM06736B

Kim, S., Laschi, C., Trimmer, B., 2013. Soft robotics: a bioinspired evolution in robotics. Trends in Biotechnology, 31(5):287-294. http://dx.doi.org/10.1016/j.tibtech.2013.03.002

Klinkel, S., Zwecker, S., Muller, R., 2013. A solid shell finite element formulation for dielectric elastomers. $A S M E$ Journal of Applied Mechanics, 80(2):021026. http://dx.doi.org/10.1115/1.4007435

Knudson, D., 2007. Fundamentals of Biomechanics, 2nd Edition. Springer, New York.

Koh, S.J.A., Zhao, X.H., Suo, Z.G., 2009. Maximal energy that can be converted by a dielectric elastomer generator. Applied Physics Letters, 94(26):262902. http://dx.doi.org/10.1063/1.3167773

Koh, S.J.A., Keplinger, C., Li, T.F., et al., 2011. Dielectric elastomer generators: how much energy can be converted? IEEE/ASME Transactions on Mechatronics, 16(1):33-41. http://dx.doi.org/10.1109/TMECH.2010.2089635

Kovacs, G., Duering, L., Michel, S., et al., 2009. Stacked dielectric elastomer actuator for tensile force transmission. Sensors and Actuators A: Physical, 155(2):299-307. http://dx.doi.org/10.1016/j.sna.2009.08.027

Kuksenok, O., Yashin, V.V., Balazs, A.C., 2008. Threedimensional model for chemoresponsive polymer gels undergoing the Belousov-Zhabotinsky reaction. Physical Review E, 78(4):041406. http://dx.doi.org/10.1103/PhysRevE.78.041406

Kwon, H.J., Yasuda, K., Gong, J.P., et al., 2014. Polyelectrolyte hydrogels for replacement and regeneration of biological tissues. Macromolecular Research, 22(3):227235 . http://dx.doi.org/10.1007/s13233-014-2045-6

La, T.G., Lau, G.K., 2013. Very high dielectric strength for dielectric elastomer actuators in liquid dielectric immersion. Applied Physics Letters, 102(19): 192905. http://dx.doi.org/10.1063/1.4806976

Lawrence, D.B., Cai, T., Hu, Z.B., et al., 2007. Temperatureresponsive semipermeable capsules composed of colloidal microgel spheres. Langmuir, 23(2):395-398. http://dx.doi.org/10.1021/la062676z 
Leng, J.S., Liu, L.W., Liu, Y.J., et al., 2009. Electromechanical stability of dielectric elastomer. Applied Physics Letters, 94(21):211901. http://dx.doi.org/10.1063/1.3138153

Li, B., Chen, H.L., Qiang J.H., et al., 2012. A model for conditional polarization of the actuation enhancement of a dielectric elastomer. Soft Matter, 8(2):311-317. http://dx.doi.org/10.1039/C1SM05847A

Li, T.F., Qu, S.X., Yang, W., 2012. Energy harvesting of dielectric elastomer generators concerning inhomogeneous fields and viscoelastic deformation. Journal of Applied Physics, 112(3):034119. http://dx.doi.org/10.1063/1.4745049

Li, T.F., Keplinger, C., Baumgartner, R., et al., 2013. Giant voltage-induced deformation in dielectric elastomers near the verge of snap-through instability. Journal of the Mechanics and Physics of Solids, 61(2):611-628. http://dx.doi.org/10.1016/j.jmps.2012.09.006

Li, T.F., Zou, Z.A., Mao, G.Y., et al., 2014. Electromechanical bi-stable behavior of a novel dielectric elastomer actuator. Journal of Applied Mechanics, 81(4):041019. http://dx.doi.org/10.1115/1.4025530

Liang, X., Cai, S.Q., 2015. Shape bifurcation of a spherical dielectric elastomer balloon under the actions of internal pressure and electric voltage. Journal of Applied Mechanics, 82(10):101002. http://dx.doi.org/10.1115/1.4030881

Lim, H.L., Hwang, Y., Kar, M., et al., 2014. Smart hydrogels as functional biomimetic systems. Biomaterials Science, 2(5):603-618. http://dx.doi.org/10.1039/c3bm60288e

Liu, J.J., Mao, G.Y., Huang, X.Q., et al., 2015. Enhanced compressive sensing of dielectric elastomer sensor using a novel structure. Journal of Applied Mechanics, 81(4):041019. http://dx.doi.org/10.1115/1.4030889

Liu, L., Chen, H.L., Sheng, J.J., et al., 2014. Experimental study on the dynamic response of inplane deformation of dielectric elastomer under alternating electric load. Smart Materials and Structures, 23(2):025037.

Liu, L.W., Liu, Y.J., Li, B., et al., 2011. Thermo-electromechanical instability of dielectric elastomers. Smart Materials and Structures, 20(7):075004.

Liu, L.W., Liu, Y.J., Luo, X.J., et al., 2012. Electromechanical instability and snap-through instability of dielectric elastomers undergoing polarization saturation. Mechanics of Materials, 55:60-72. http://dx.doi.org/10.1016/j.mechmat.2012.07.009

Liu, L.W., Zhang, Z., Liu, Y.J., et al., 2014a. Failure modeling of folded dielectric elastomer actuator. Science China: Physics, Mechanics \& Astronomy, 57(2):263-272. http://dx.doi.org/10.1007/s11433-013-5047-z

Liu, L.W., Yu, K., Liu, Y.J., et al., 2014b. Polar elastic dielectric of large electrocaloric effect and deformation. Mechanics of Materials, 69(1):71-92. http://dx.doi.org/10.1016/j.mechmat.2013.09.006

Liu, L.W., Liu, Y.J., Yu, K., et al., 2014c. Thermoelectrome- chanical stability of dielectric elastomers undergoing temperature variation. Mechanics of Materials, 72:33-45. http://dx.doi.org/10.1016/j.mechmat.2013.05.013

Liu, L.W., Zhang, Z., Li, J.R., et al., 2015. Stability of dielectric elastomer/carbon nanotube composites coupling electrostriction and polarization. Composites Part B: Engineering, 78(1):35-41. http://dx.doi.org/10.1016/j.compositesb.2015.03.069

Liu, Y.J., Liu, L.W., Zhang, Z., et al., 2008. Comment on method to analyze electromechanical stability of dielectric elastomers. Applied Physics Letters, 93(10):106101. http://dx.doi.org/10.1063/1.2979236

Liu, Y.J., Liu, L.W., Sun, S.H., et al., 2009a. An investigation on electromechanical stability of dielectric elastomers undergoing large deformation. Smart Materials and Structures, 18(9):095040.

Liu, Y.J., Liu, L.W., Zhang, Z., et al., 2009b. Dielectric elastomer film actuators: characterization, experiment and analysis. Smart Materials and Structures, 18(9): 095024.

Liu, Y.J., Liu, L.W., Zhang, Z., et al., 2010. Analysis and manufacture of an energy harvester based on a MooneyRivlin-type dielectric elastomer. Europhysics Letters, 90(3):36004. http://dx.doi.org/10.1209/0295-5075/90/36004

Lochmatter, P., Kovacs, G., Wissler, M., 2007. Characterization of dielectric elastomer actuators based on a viscohyperelastic film model. Smart Materials and Structures, 16(2):477-486.

Lu, T.Q., Huang, J.S., Jordi, C., et al., 2012. Dielectric elastomer actuators under equal-biaxial forces, uniaxial forces, and uniaxial constraint of stiff fibers. Soft Matter, 8(22):6167-6173. http://dx.doi.org/10.1039/c2sm25692d

Lu, T.Q., Foo, C.C., Huang, J.S., et al., 2014. Highly deformable actuators made of dielectric elastomers clamped by rigid rings. Journal of Applied Physics, 115(18):184105. http://dx.doi.org/10.1063/1.4876722

Lucantonio, A., Nardinocchi, P., 2012. Reduced models of swelling-induced bending of gel bars. International Journal of Solids and Structures, 49(11-12):1399-1405. http://dx.doi.org/10.1016/j.ijsolstr.2012.02.025

Mao, G.Y., Li, T.F., Zou, Z.A., et al., 2014. Prestretch effect on snap-through instability of inflated tubular elastomeric balloons. International Journal of Solids and Structures, 51(11-12):2109-2115. http://dx.doi.org/10.1016/j.ijsolstr.2014.02.013

Mao, G.Y., Huang, X.Q., Liu, J.J., et al., 2015. Dielectric elastomer peristaltic pump module with finite deformation. Smart Materials and Structures, 24(7):075026.

Marckmann, G., Verron, E., 2006. Comparison of hyperelastic models for rubber-like materials. Rubber Chemistry and Technology, 79(5):835-858. http://dx.doi.org/10.5254/1.3547969

Marcombe, R., Cai, S.Q., Hong, W., et al., 2010. A theory of 
constrained swelling of a $\mathrm{pH}$-sensitive hydrogel. Soft Matter, 6(4):784-793.

http://dx.doi.org/10.1039/b917211d

McKay, T., O’Brien, B., Calius, E., et al., 2010. An integrated, self priming dielectric elastomer generator. Applied Physics Letters, 97(6):062911. http://dx.doi.org/10.1063/1.3478468

McKay, T.G., O’Brien, B.M., Calius, E.P., et al., 2011. Soft generators using dielectric elastomers. Applied Physics Letters, 98(14):142903. http://dx.doi.org/10.1063/1.3572338

Mooney, M., 1940. A theory of large elastic deformation. Journal of Applied Physics, 11(9):582-592. http://dx.doi.org/10.1063/1.1712836

Moscardo, M., Zhao, X.H., Suo, Z.G., et al., 2008. On designing dielectric elastomer actuators. Journal of Applied Physics, 104(9):093503. http://dx.doi.org/10.1063/1.3000440

Mutlu, R., Alici, G., Xiang, X., et al., 2014. Electromechanical modelling and identification of electroactive polymer actuators as smart robotic manipulators. Mechatronics, 24(3):241-251. http://dx.doi.org/10.1016/j.mechatronics.2014.02.002

Nguyen, C.H., Alici, G., Mutlu, R., 2014b. A compliant translational mechanism based on dielectric elastomer actuators. Journal of Mechanical Design, 136(6):061009. http://dx.doi.org/10.1115/1.4027167

Nguyen, C.T., Phung, H., Nguyen, T.D., et al., 2014a. A small biomimetic quadruped robot driven by multistacked dielectric elastomer actuators. Smart Materials and Structures, 23(6):065005.

Ogden, R.W., 1972. Large deformation isotropic elasticity-on the correlation of theory and experiment for incompressible rubber-like solids. Proceedings of the Royal Society A: Mathematical, Physical and Engineering Sciences, 326(1567):565-584. http://dx.doi.org/10.1098/rspa.1972.0026

O’Halloran, A., O’Malley, F., McHugh, P., 2008. A review on dielectric elastomer actuators, technology, applications, and challenges. Journal of Applied Physics, 104(7): 071101 . http://dx.doi.org/10.1063/1.2981642

Otake, M., 2010. Electroactive Polymer Gel Robots: Modelling and Control of Artificial Muscles. Springer, Berlin. http://dx.doi.org/10.1007/978-3-540-44705-4

Park, H.S., Nguyen, T.D., 2013. Viscoelastic effects on electromechanical instabilities in dielectric elastomers. Soft Matter, 9(4):1031-1042. http://dx.doi.org/10.1039/C2SM27375F

Pelrine, R., Kornbluh, R., Pei, Q.B., et al., 2000. High-speed electrically actuated elastomers with strain greater than 100\%. Science, 287(5454):836-839. $\mathrm{http} / / / \mathrm{dx}$.doi.org/10.1126/science.287.5454.836

Plante, J.S., Dubowsky, S., 2006. Large-scale failure modes of dielectric elastomer actuators. International Journal of Solids and Structures, 43(25-26):7727-7751.

http://dx.doi.org/10.1016/j.ijsolstr.2006.03.026

Plante, J.S., Dubowsky, S., 2007. On the performance mechanisms of dielectric elastomer actuators. Sensors and Actuators A: Physical, 137(1):96-109. http://dx.doi.org/10.1016/j.sna.2007.01.017

Qu, S.X., Suo, Z.G., 2012. A finite element method for dielectric elastomer. Acta Mechanica Solida Sinica, 25(5):459-466. http://dx.doi.org/10.1016/S0894-9166(12)60040-8

Qu, S.X., Li, K., Li, T.F., et al., 2012. Rate dependent stressstretch relation of dielectric elastomers subjected to pure shear like loading and electric field. Acta Mechanica Solida Sinica, 25(5):542-549. http://dx.doi.org/10.1016/S0894-9166(12)60048-2

Rivlin, R.S., 1948. Large elastic deformations of isotropic materials. IV. further developments of the general theory. Philosophical Transactions of the Royal Society of London. Series A: Mathematical and Physical Sciences, 241(835):379-397. http://dx.doi.org/10.1098/rsta.1948.0024

Rotzetter, A.C.C., Schumacher, C.M., Bubenhofer, S.B., et al., 2012. Thermoresponsive polymer induced sweating surfaces as an efficient way to passively cool buildings. Advanced Materials, 24(39):5352-5356. http://dx.doi.org/10.1002/adma.201202574

Shahinpoor, M., 2003. Ionic polymer-conductor composites as biomimetic sensors, robotic actuators and artificial muscles-a review. Electrochimica Acta, 48(14-16):23432353. http://dx.doi.org/10.1016/S0013-4686(03)00224-X

Shahinpoor, M., Bar-Cohen, Y., Simpson, J.O., et al., 1998. Ionic polymer-metal composites (IPMCs) as biomimetic sensors, actuators and artificial muscles-a review. Smart Materials and Structures, 7(6):R15-R30.

Shahinpoor, M., Kim, K.J., Mojarrad, M., 2007. Artificial Muscles: Applications of Advanced Polymeric Nanocomposites. Taylor \& Francis, London.

Shankar, R., Ghosh, T.K., Spontak, R.J., 2007. Dielectric elastomers as next-generation polymeric actuators. Soft Matter, 3(9):1116-1129. http://dx.doi.org/10.1039/b705737g

Shian, S., Diebold, R.M., Clarke, D.R., 2013. Tunable lenses using transparent dielectric elastomer actuators. Optics Express, 21(7):8669-8676. http://dx.doi.org/10.1364/OE.21.008669

Siboni, M.H., Castañeda, P.P., 2014. Fiber-constrained, dielectric-elastomer composites: finite-strain response and stability analysis. Journal of the Mechanics and Physics of Solids, 68:211-238. http://dx.doi.org/10.1016/j.jmps.2014.03.008

Son, S., Goulbourne, N.C., 2009. Finite deformations of tubular dielectric elastomer sensors. Journal of Intelligent Material Systems and Structures, 20(18):2187-2199. http://dx.doi.org/10.1177/1045389X09350718

Son, S.I., Pugal, D., Hwang, T., et al., 2012. Electromechanically driven variable-focus lens based on transparent 
dielectric elastomer. Applied Optics, 51(15):2987-2996. http://dx.doi.org/10.1364/AO.51.002987

Suo, Z.G., 2010. Theory of dielectric elastomers. Acta Mechanica Solida Sinica, 23(6):549-578. http://dx.doi.org/10.1016/S0894-9166(11)60004-9

Suo, Z.G., Zhao, X.H., Greene, W.H., 2008. A nonlinear field theory of deformable dielectrics. Journal of the Mechanics and Physics of Solids, 56(2):467-486. http://dx.doi.org/10.1016/j.jmps.2007.05.021

Tagarielli, V.L., Hildick-Smith, R., Huber, J.E., 2012. Electro-mechanical properties and electrostriction response of a rubbery polymer for EAP applications. International Journal of Solids and Structures, 49(2324):3409-3415.

http://dx.doi.org/10.1016/j.ijsolstr.2012.07.018

Toh, W., Liu, Z.S., Ng, T.Y., et al., 2013. Inhomogeneous large deformation kinetics of polymeric gels. International Journal of Applied Mechanics, 5(1):1350001. http://dx.doi.org/10.1142/S1758825113500014

Toh, W., Ng, T.Y., Liu, Z.S., et al., 2014. Deformation kinetics of $\mathrm{pH}$-sensitive hydrogels. Polymer International, 63(9): $1578-1583$. http://dx.doi.org/10.1002/pi.4652

Treloar, L.R.G., 1943. The elasticity of a network of longchain molecules-II. Transactions of the Faraday Society, 39(36):241-246. http://dx.doi.org/10.1039/tf9433900241

Treloar, L.R.G., 1975. The Physics of Rubber Elasticity, 3rd Edition. Oxford University Press, Oxford, UK.

Vertechy, R., Frisoli, A., Bergamasco, M., et al., 2012. Modeling and experimental validation of buckling dielectric elastomer actuators. Smart Materials and Structures, 21(9):094005.

Wallace, G.G., Spinks, G.M., Kane-Maguire, L.A.P., et al., 2009. Conductive Electroactive Polymers: Intelligent Polymer Systems. Taylor \& Francis, London.

Wang, E., Desai, M.S., Lee, S., 2013. Light-controlled graphene-elastin composite hydrogel actuators. Nano Letters, 13(6):2826-2830. http://dx.doi.org/10.1021/n1401088b

Wang, H.M., Zhu, Y.L., Wang, L., et al., 2012a. Experimental investigation on energy conversion for dielectric electroactive polymer generator. Journal of Intelligent Material Systems and Structures, 23(8):885-895. http://dx.doi.org/10.1177/1045389X12442011

Wang, H.M., Cai, S.Q., Carpi, F., et al., 2012b. Computational model of hydrostatically coupled dielectric elastomer actuators. Journal of Applied Mechanics, 79(3): 031008. http://dx.doi.org/10.1115/1.4005885

Wang, H.M., Lei, M., Cai, S.Q., 2013. Viscoelastic deformation of a dielectric elastomer membrane subject to electromechanical loads. Journal of Applied Physics, 113(21):213508. http://dx.doi.org/10.1063/1.4807911

Wang, J., Nguyen, T.D., Park, H.S., 2014. Electrostatically driven creep in viscoelastic dielectric elastomers. Journal of Applied Mechanics, 81(5):051006. http://dx.doi.org/10.1115/1.4025999

Wang, M., Guth, E., 1952. Statistical theory of networks of non-Gaussian flexible chains. Journal of Chemical Physics, 20(7):1144-1157. http://dx.doi.org/10.1063/1.1700682

Wissler, M., Mazza, E., 2005. Modeling of a pre-strained circular actuator made of dielectric elastomers. Sensors and Actuators A: Physical, 120(1):184-192. http://dx.doi.org/10.1016/j.sna.2004.11.015

Wissler, M., Mazza, E., 2007. Mechanical behavior of an acrylic elastomer used in dielectric elastomer actuators. Sensors and Actuators A: Physical, 134(2):494-504. http://dx.doi.org/10.1016/j.sna.2006.05.024

Wu, P.D., van der Giessen, E., 1993. On improved network models for rubber elasticity and their applications to orientation hardening in glassy-polymers. Journal of the Mechanics and Physics of Solids, 41(3):427-456. http://dx.doi.org/10.1016/0022-5096(93)90043-F

Wu, Z., Zhong, Z., 2013. Inhomogeneous equilibrium swelling of core-shell-coating gels. Soft Materials, 11(2): 215-220. http://dx.doi.org/10.1080/1539445X.2012.617644

Yamaue, T., Doi, M., 2004. Theory of one-dimensional swelling dynamics of polymer gels under mechanical constraint. Physical Review E, 69(4):041402. http://dx.doi.org/10.1103/PhysRevE.69.041402

Yamaue, T., Doi, M., 2005. The stress diffusion coupling in the swelling dynamics of cylindrical gels. Journal of Chemical Physics, 122(8):084703. http://dx.doi.org/10.1063/1.1849153

Yashin, V.V., Balazs, A.C., 2006. Modeling polymer gels exhibiting self-oscillations due to the BelousovZhabotinsky reaction. Macromolecules, 39(6):20242026. http://dx.doi.org/10.1021/ma052622g

Yashin, V.V., Kuksenok, O., Dayal, P., et al., 2012. Mechano-chemical oscillations and waves in reactive gels. Reports on Progress in Physics, 75(6):066601. http://dx.doi.org/10.1088/0034-4885/75/6/066601

Yeoh, O.H., 1990. Characterization of elastic properties of carbon black filled rubber vulcanizates. Rubber Chemistry and Technology, 63(5):792-805. http://dx.doi.org/10.5254/1.3538289

Yong, H.D., He, X.Z., Zhou, Y.H., 2012. Electromechanical instability in anisotropic dielectric elastomers. International Journal of Engineering Science, 50(1):144-150. http://dx.doi.org/10.1016/j.ijengsci.2011.08.007

Zarzar, L.D., Liu, Q.H., He, X.M., et al., 2012. Multifunctional actuation systems responding to chemical gradients. Soft Matter, 8(32):8289-8293. http://dx.doi.org/10.1039/c2sm26064f

Zhao, X.H., Suo, Z.G., 2007. Method to analyze electromechanical stability of dielectric elastomers. Applied 
Physics Letters, 91(6):061921.

http://dx.doi.org/10.1063/1.2768641

Zhao, X.H., Suo, Z.G., 2008a. Electrostriction in elastic dielectrics undergoing large deformation. Journal of Applied Physics, 104(12):123530. http://dx.doi.org/10.1063/1.3031483

Zhao, X.H., Suo, Z.G., 2008b. Method to analyze programmable deformation of dielectric elastomer layers. Applied Physics Letters, 93(25):251902. http://dx.doi.org/10.1063/1.3054159

Zhao, X.H., Wang, Q.M., 2014. Harnessing large deformation and instabilities of soft dielectrics: theory, experiment, and application. Applied Physics Reviews, 1(2):021304. http://dx.doi.org/10.1063/1.4871696

Zhao, X.H., Hong, W., Suo, Z.G., 2007. Electromechanical hysteresis and coexistent states in dielectric elastomers. Physical Review B, 76(13):134113. http://dx.doi.org/10.1103/PhysRevB.76.134113

Zhao, X.H., Hong, W., Suo, Z.G., 2008. Inhomogeneous and anisotropic equilibrium state of a swollen hydrogel containing a hard core. Applied Physics Letters, 92(5): 051904 .

http://dx.doi.org/10.1063/1.2840158

Zhao, X.H., Koh, S.J.A., Suo, Z.G., 2011. Nonequilibrium thermodynamics of dielectric elastomers. International Journal of Applied Mechanics, 3(2):203-217. http://dx.doi.org/10.1142/S1758825111000944

Zhou, J., Jiang, L., Khayat, R.E., 2013. Failure analysis of a dielectric elastomer plate actuator considering boundary constraints. Journal of Intelligent Material Systems and Structures, 24(14):1667-1674. http://dx.doi.org/10.1177/1045389X13483025

Zhu, J., 2015. Instability in nonlinear oscillation of dielectric elastomers. Journal of Applied Mechanics, 82(6): 061001 .

http://dx.doi.org/10.1115/1.4030075
Zou, Z.A., Li, T.F., Qu, S.X., et al., 2014. Active shape control and phase coexistence of dielectric elastomer membrane with patterned electrodes. Journal of Applied Mechanics, 81(3):031016.

http://dx.doi.org/10.1115/1.4025416

\section{中文概要}

\section{题 目：人工肌肉本构模型的综述}

摘 要: 人工肌肉是指具有类似肌肉特性的材料, 这些 材料在外界激励下, 可以实现大变形, 且响应 速度快。本文总结两类人工肌肉本构模型的研 究成果: 一类是介电高弹体, 另一类是响应性 凝胶。本文中提到的本构模型仅限于用自由能 函数导出的情形。对于介电高弹体材料, 分别 综述超弹性模型和粘性超弹性模型。在超弹性 模型中, 列出目前研究中使用较多的一些本构 模型的自由能函数具体表达式; 比较 neoHookean、Gent、Arruda-Boyce 和 Ogden 四种模 型在单轴拉伸和等双轴拉伸两种情形下的名义 应力-伸长曲线; 给出了考虑一些重要因素的研 究模型, 这些因素包括材料可压缩性、取向极 化、变介电常数、热耦合、受纤维约束、流体 耦合以及空气耦合等。对于响应性凝胶, 分别 综述水凝胶、 $\mathrm{pH}$ 敏感性凝胶、温度敏感性凝 胶、聚电解质凝胶以及反应性凝胶等的本构模 型。这些精确、可靠和有效的本构模型, 将有 助于开展人工肌肉系统的性能分析和预测, 甚 至揭示其内在特性和本质规律。

关键词：本构模型; 人工肌肉; 介电高弹体; 响应性凝 胶; 自由能函数 